\title{
Hematite Dodecahedron Crystals with High-index Facets Grown and Grafted on One Dimensional Structures for Efficient Photoelectrochemical $\mathrm{H}_{2}$ Generation
}

Lei Wang,* Nhat Truong Nguyen, Beibei Zhang, Zhiqiang Shen, Patrik Schmuki,* and Yingpu Bi*

Prof. Lei Wang, Beibei Zhang, Zhiqiang Shen, Prof. Yingpu Bi

State Key Laboratory for Oxo Synthesis and Selective Oxidation, National Engineering

Research Center for Fine Petrochemical Intermediates, Lanzhou Institute of Chemical Physics, Chinese Academy of Sciences, 730000 Lanzhou, China.

E-mail: wanglei@licp.cas.cn; yingpubi@licp.cas.cn

Dr. Nhat Truong Nguyen, , Prof. Patrik Schmuki

Department of Materials Science and Engineering, WW4-LKO, University of Erlangen-

Nuremberg, Martensstrasse 7, D-91058 Erlangen, Germany.

E-mail: schmuki@ww.uni-erlangen.de

Prof. Patrik Schmuki

Department of Chemistry, King Abdulaziz University, 80203 Jeddah, Saudi Arabia.

Keywords: Hematite dodecahedron with high-index facets, one dimensional nanoflakes, charge transportation, light absorption, solar water splitting.

Link to the published articles:

https://www.sciencedirect.com/science/article/abs/pii/S2211285518303549 
$\mathrm{Fe}_{2} \mathrm{O}_{3}$ polyhedrons are one of the most promising morphologies for photoelectrochemical water splitting. In spite of recent reports on the successful synthesis of various $\mathrm{Fe}_{2} \mathrm{O}_{3}$ polyhedrons, the fabrication of defined photoelectrodes by anchoring the polyhedron in a suitable configuration remains a great challenge. Herein, we introduce a synthetic strategy to prepare $\mathrm{Fe}_{2} \mathrm{O}_{3}$ dodecahedrons with high-index $\{112\}$ facets directly anchored on a one dimensional $\mathrm{Fe}_{2} \mathrm{O}_{3}$ nanoflake ( $\{110\}$ facets) electrode. Key is that the $\mathrm{Fe}_{2} \mathrm{O}_{3}$ nanoflakes act as seeds for the initiation of the growth of dodecahedral nanocrystals from an iron nitrate solution. The initial single crystals consist of $\mathrm{Fe}_{3} \mathrm{O}_{4}$ with exposed $\{110\}$ basal surfaces that then in a thermal step can be converted to hematite with $\{112\}$ facets. The resulting single crystal (bi-crystal) hematite photoanode demonstrates a high efficiency for solar water splitting with an excellent photoresponse due to the synergistic effect of direct grafting of the light harvesting and reactive polyhedron and the 1D transport geometry. Under optimized conditions the hematite polyhedrons on nanoflake-structure show photocurrent densities of $2.4 \mathrm{~mA} \mathrm{~cm}^{-2}$ at $1.23 \mathrm{~V}_{\mathrm{RHE}}$ and $3.5 \mathrm{~mA} \mathrm{~cm}^{-2}$ at $1.5 \mathrm{~V}_{\text {RHE }}$ under $\mathrm{AM} 1.5 \mathrm{G}$ simulated sunlight.

\section{Introduction}

Photoelectrochemical (PEC) water splitting reactions have been regarded as one of the most promising approaches to convert solar energy into chemical energy, by direct hydrogen production from natural water and sunlight. ${ }^{[1-5]}$ Hematite $\left(\alpha-\mathrm{Fe}_{2} \mathrm{O}_{3}\right)$, one of the interesting ntype metal oxide semiconductors, has been extensively applied for PEC photoelectrodes due to its chemical stability, abundance in the earth, and favorable optical bandgap $(\sim 2.1 \mathrm{eV})$ that allows for light harvesting of approximate $40 \%$ of the solar spectrum. However, its performance has been severely limited by the conflict between light absorption $\left(\alpha^{-1}=0.12 \mu \mathrm{m}\right.$ at $550 \mathrm{~nm}$ ) and charge separation (short hole diffusion length of 2-4 nm). ${ }^{[6-10]}$ Therefore, it is necessary to tackle these issues by an optimized design of photoanode structures and taking advantage of some intrinsic $\mathrm{Fe}_{2} \mathrm{O}_{3}$ properties. 
Recently the rational design and synthesis of $\alpha-\mathrm{Fe}_{2} \mathrm{O}_{3}$ nanocrystals with tunable morphology and properties has drawn considerable research interest. ${ }^{[1-14]}$ It has been shown that the precise fabrication of crystals with a specific shape and orientation at the nanoscale level can enhance the performance of hematite in many applications, e.g. catalysis, solar conversion et al. Such shape effects inherently result from the atomic arrangement, electronic structure, and chemical reactivity of different exposed crystal facets. ${ }^{[15,16]}$ For instance, the energy levels of conduction and valence bands of different crystal facets on hematite are different due to the atomic arrangements characteristic at these facets, and these differences may serve as the driving force for the separation of electron and hole or may provide states that promote charge transfer across the interface, factors that are essential for the photocatalytic activity and reactivity. ${ }^{[17]}$ Recently the application of $\alpha-\mathrm{Fe}_{2} \mathrm{O}_{3}$ polyhedrons to the photoelectrochemical field has demonstrated these structures to be highly promising for enhanced PEC water oxidation. ${ }^{[18-20]}$ For instance, dodecahedral and octodecahedral $\alpha-\mathrm{Fe}_{2} \mathrm{O}_{3}$ particles prepared via a hydrothermal method in the presence of iron chloride and $\mathrm{F}^{-}$anions showed a better photoelectrochemical and photocatalytic performance and a high stability. ${ }^{[18,19]}$ This beneficial effect has been ascribed to the higher activity of facets of the surface structure (namely (104) planes) of polyhedron nanocrystals that facilitate charge transfer.

Despite the successful synthesis of such $\alpha-\mathrm{Fe}_{2} \mathrm{O}_{3}$ polyhedron structures, the relatively low specific surface area of the single crystals (typically micrometer size scale) strongly limits its PEC performance. Furthermore, sintered nanoparticle films suffer from a drastic decrease in electron mobility, due to abundant grain boundaries and associated defects, combined with a lack of directional charge transfer to the back contact. ${ }^{[20]}$ Work of Fang and coworkers $^{[21]}$ has recently shown the successful fabrication of tetrakaidecahedronal $\alpha-\mathrm{Fe}_{2} \mathrm{O}_{3}$ particles coupled with graphene oxide. The high PEC performance of $\alpha-\mathrm{Fe}_{2} \mathrm{O}_{3} /$ graphene composite has been ascribed to the coupling of graphene, facilitating the charge separation and transfer and 
hindering the charge recombination of photogenerated electron-hole pairs. Alternatively, onedimensional (1D) nanostructures, e.g. nanotubes and nanorods, provide a directional charge transport for electrons and short holes transport distances, which lead to an improved charge separation and reduced bulk recombination. ${ }^{[22]}$ Therefore, an approach to combine $\alpha-\mathrm{Fe}_{2} \mathrm{O}_{3}$ polyhedrons with reactive facets onto one dimensional structures is a promising route for taking advantages of both structures to achieve activity and transport improvement of hematite photoanodes.

In this work, we show that $\mathrm{Fe}_{2} \mathrm{O}_{3}$ 1D-nanoflake layers grown on a metallic Fe substrate can act very effectively as seeds for the initiation and growth of dodecahedral $\mathrm{Fe}_{3} \mathrm{O}_{4}$ with defined facets (exposing the $\{110\}$ basal surfaces). As a result, on the 1D nanoflake, inter-grown crystals are formed that after a suitable annealing treatment become hematite polyhedrons with reactive high-index planes namely $\{112\}$. These $\alpha-\mathrm{Fe}_{2} \mathrm{O}_{3}$ polyhedrons anchored on the NF-structure provide an excellent photoanode. The dodecahedral $\alpha-\mathrm{Fe}_{2} \mathrm{O}_{3}$ provides hole transfer reactivity, while the 1D NFs serve not only as a seeding layer inducing the formation of polyhedrons but also act as an efficient electron transport medium, to the back side. Additionally, the combined polyhedron on NF structure can provide an efficient geometry for an increased light absorption, and finally Sn doping of the dodecahedral $\alpha-\mathrm{Fe}_{2} \mathrm{O}_{3}$ anchored on 1D NFs can be used to achieve further enhancement in PEC water splitting due to a combined effect of three-dimensional structure and the Sn doping.

\section{Results and discussion}

Scheme 1 illustrates the synthesis process of dodecahedral $\alpha-\mathrm{Fe}_{2} \mathrm{O}_{3}$ crystals on the hematite NFs. First we formed an ordered layer of $\alpha-\mathrm{Fe}_{2} \mathrm{O}_{3} \mathrm{NFs}$ by a facile thermal oxidation of iron foil at $400{ }^{\circ} \mathrm{C}$ for $2-3 \mathrm{~h}$ (Scheme 1a), as described in the SI. Then, the as-grown NF samples were immersed in an iron nitrate solution for various times at room temperature to induce the initiation and growth of $\mathrm{Fe}_{3} \mathrm{O}_{4}$ crystallites on the NFs (see experimental for details). At early 
reaction stages, the primary nuclei are formed (Scheme 1b). The primary nuclei then grow further into irregular nanocrystals (Scheme 1c) that gradually evolve into 3D a polyhedron structure (Scheme 1d). The dodecahedral $\mathrm{Fe}_{3} \mathrm{O}_{4}$ can finally be completely transformed to $\alpha$ $\mathrm{Fe}_{2} \mathrm{O}_{3}$ dodecahedron by a thermal treatment in air at $600{ }^{\circ} \mathrm{C}$ (Scheme 1e). Remarkably the dodecahedrons show a high density of exposed $\{112\}$ facets.

Figure 1a shows the scanning electron microscopy (SEM) image of as-grown $\alpha-\mathrm{Fe}_{2} \mathrm{O}_{3}$ NFs. The geometry of these flakes is crucial to initiate dodecahedral nanocrystal growth. The individual flakes with sharp apexes are 1.0-2.5 $\mu \mathrm{m}$ in length, 100-400 nm thick at the base, and the thickness tapers down to $\sim 10 \mathrm{~nm}$ at the tip. The X-ray diffraction (XRD) pattern (Figure 1h) matches well with the crystal structure of hematite (JCPDS No. 33-0664) and magnetite (JCPDS No. 19-0629). The magnetite is observable in the SEM image underneath the NFs (inset of Figure 1a). Raman spectroscopy (Figure 1i) exhibits peaks at 222, 245, 289, 407, 495, and $609 \mathrm{~cm}^{-1}$ that can be assigned to hematite for the NFs sample. ${ }^{[23,24]}$ After immersion in the $\mathrm{Fe}\left(\mathrm{NO}_{3}\right)_{3}$ aqueous solution for the NFs sample, nanopolyhedron particles have been successfully formed with an average particle size of $150 \mathrm{~nm}$ (Figures $\mathbf{1 b}$ and c). The XRD pattern (Figure 1h) displays a small peak at $37.1^{\circ}$ during the synthetic process, which can be attributed to the (222) crystal planes of the $\mathrm{Fe}_{3} \mathrm{O}_{4}$ nanopolyhedrons. ${ }^{[11]}$ Except for the hematite, the Raman bands (Figures 1i) at 275, 387, and $663 \mathrm{~cm}^{-1}$ can be clearly resolved, corresponding to the spectral characteristics of magnetite. ${ }^{[23]}$ Additionally, together with the XRD and Raman results, transmission electron microscopy (TEM) images (Figure 1e and f) and the corresponding selected area electron diffraction (SAED) pattern (inset of Figure 1f) confirm that the iron oxide is mainly hematite with the presence of a secondary magnetite phase. The lattice spacing of $0.29 \mathrm{~nm}$ in the polyhedron corresponds to the (220) plane of magnetite in Figure 1f. After the thermal transformation (annealed at $600{ }^{\circ} \mathrm{C}$ ) of the polyhedron $\mathrm{Fe}_{3} \mathrm{O}_{4}$ to $\alpha-\mathrm{Fe}_{2} \mathrm{O}_{3}$, the polyhedron shape and morphology remain intact, i.e. no change is observed for the polyhedron $\alpha-\mathrm{Fe}_{2} \mathrm{O}_{3}$ on the NFs (Figure 1d). The TEM image 
given in Figure $1 \mathrm{~g}$ exhibits a lattice spacing of $0.37 \mathrm{~nm}$, and the value can be assigned to the lattice fringe of $\{112\}$ planes confirming a hematite crystal structure for the converted polyhedrons. Moreover, the Raman peaks (Figures 1i) at 275, 387, and $663 \mathrm{~cm}^{-1}$ corresponding to the magnetite decrease significantly after the second thermal annealing treatment, accompanied with an increased intensity of hematite. Furthermore, Sn treated polyhedron nanoparticles were obtained by dropping a $0.2 \mathrm{M} \mathrm{SnCl}_{4} \cdot 5 \mathrm{H}_{2} \mathrm{O}$ ethanol solution on the dodecahedral $\mathrm{Fe}_{3} \mathrm{O}_{4}$ on NFs followed by the thermal treatment at $600{ }^{\circ} \mathrm{C}$ (Figures $\mathbf{S 1}$ and S2). The presence of Sn in polyhedron nanoparticles anchored on NFs was confirmed by Xray photoelectron spectra (XPS), in which two peaks at $486.8 \mathrm{eV}\left(\mathrm{Sn} 3 \mathrm{~d}_{5 / 2}\right)$ and $495.2 \mathrm{eV}(\mathrm{Sn}$ $3 \mathrm{~d}_{3 / 2}$ ) assigned to $\mathrm{Sn}^{4+}$ appear for the $\mathrm{Sn}$ doped hematite (Figure S2). The Raman spectrum at peak of $\sim 660 \mathrm{~cm}^{-1}$ shows a slightly increased and broadened peak compared to the un-doped sample (Figure S3b).

To further understand the formation process of $\mathrm{Fe}_{3} \mathrm{O}_{4}$ polyhedrons on the flakes, a series of time- and concentration-dependent experiments were conducted. Time and concentration (as shown in Figures S4-S7) play an important role in tuning the particle shape. Figure S4 shows SEM images of the polyhedrons on the NFs after different growth steps. This sequence suggests that during the reaction iron hydroxides $\left(\mathrm{Fe}(\mathrm{OH})_{3}\right.$ or $\left.\mathrm{FeOOH}\right)$ are transformed to crystalized iron oxide, ${ }^{[24]}$ and the sizes of the as-synthesized $\mathrm{Fe}_{3} \mathrm{O}_{4}$ polyhedrons are dependent mainly on the reaction time. Moreover due to the acid solution, the iron substrate corrodes and causes additional $\mathrm{Fe}^{3+}$ and $\mathrm{Fe}^{2+}$ release into the $\mathrm{NO}_{3}{ }^{-}$solution. At the beginning $(\sim 10 \mathrm{~h})$, small-sized nanoparticles initiate on the NFs orientation by the hydrolysis of iron nitrate (Figure S4c). After a synthesis time for 16-20 h, we obtain cubic shapes of nanocrystals with 6 faces, 8 vertices and 12 edges (Figure S4d and e). The size of these irregular shaped nanocrystals is in the range of 50-150 $\mathrm{nm}$. After a reaction time of $24 \mathrm{~h}$, nanocrystals of dodecahedron shape are obtained containing 12 faces with 20 vertices and 30 edges (Figure S4f) dominated by $\{110\}$ facets - the crystal facet distribution increasingly becomes more 
uniform (see NFs after $48 \mathrm{~h}$ reaction time in Figure $\mathbf{S 4 g}$ ). After $72 \mathrm{~h}$ (Figure S4h), the polyhedron particles reach their final features. The formation of single crystals with different facets can be attributed to the surface energies of different facets and the relative growth rates of different facets. ${ }^{[11,25,26]}$ As a result, the facet with a slower growth rate will be exposed more on the nanocrystal surface. The preferential growth at a specific face leads to the final formation of $\mathrm{Fe}_{3} \mathrm{O}_{4}$ enclosed by $\{110\}$ facets. Moreover, the three-dimensional nanocrystals comply with Euler's formula, ${ }^{[27]}$ which links the number the vertices $(\mathrm{V})$, faces $(\mathrm{F})$, and edges (E) of a polyhedron as $\mathrm{V}+\mathrm{F}-\mathrm{E}=2$. Therefore, the synthesized nanocrystals after the longest growth are geometrically most stable. These $\{110\}$ faceted $\mathrm{Fe}_{3} \mathrm{O}_{4}$ polyhedrons after thermal treatment convert to $\{112\}$ faceted $\mathrm{Fe}_{2} \mathrm{O}_{3}$.

For comparison, various precursor concentrations for a synthesis time of $24 \mathrm{~h}$ were examined (Figure S7). Lower $\mathrm{Fe}\left(\mathrm{NO}_{3}\right)_{3}$ concentrations (1 and $2.5 \mathrm{mM}$ ) only induce the nanoparticles grafted on the NFs orientation. For $\mathrm{Fe}\left(\mathrm{NO}_{3}\right)_{3}$ concentrations increased to $5 \mathrm{mM}$, regular polyhedron nanoparticles with a typical size of $\sim 150 \mathrm{~nm}$ and a straight edge are formed on the NFs. To further understand the role of $\mathrm{NO}_{3}{ }^{-}$ions on the phase transition process, the precursor of $\mathrm{Fe}\left(\mathrm{NO}_{3}\right)_{3}$ was substituted by $\mathrm{FeCl}_{3}$ under the same immersion conditions. This did not lead to any crystallite initiation but only a uniform 1-2 nm amorphous FeOOH layer was formed on the NFs (Figure S8). ${ }^{[28]}$ Alternatively, a fluorine-doped $\mathrm{SnO}_{2}$ (FTO) substrate was used, replacing $\alpha-\mathrm{Fe}_{2} \mathrm{O}_{3} \mathrm{NFs}$ on iron substrate, and was exposed to the same condition of $\mathrm{Fe}\left(\mathrm{NO}_{3}\right)_{3}$ solution. On this substrate only a filiform FeOOH layer is obtained (Figure S9). These results reveal that for the formation of a polyhedron morphology, hematite NFs as a seeding layer are essential to successfully grow dodecahedrons that are crystallographically grafted to the substrate.

Interestingly the inter-grown $\mathrm{Fe}_{2} \mathrm{O}_{3}$ bi-crystal structures also provide an improved light absorption morphology as apparent from ultraviolet-visible (UV-vis) absorption spectra (Figures 1j and S10). The light absorption of polyhedron hematite with $\{112\}$ facets 
anchored on NFs is significantly higher in comparison with pristine NFs with $\{110\}$ facets over the entire wavelength range, but especially for longer wavelength $(600-700 \mathrm{~nm})$. This can be ascribed to a higher degree of light scattering within these structures, especially highindex facets. ${ }^{[29,30]}$ Also the band gap energy $\left(E_{\mathrm{g}}\right)$ can be elucidated by extrapolating the linear portion of $(\alpha h v)^{1 / 2}$ versus the $(h v)$ plot. On the basis of the results (inset of Figure 1j), the band gaps for the hematite NFs and polyhedron on NFs are $2.1 \mathrm{eV}$ and $1.95 \mathrm{~V}$, respectively. This is in line with the indirect (phonon-assisted) band gap of hematite, reported to be $1.9 \mathrm{eV}$ to $2.3 \mathrm{eV}$ dependent on crystal orientation. ${ }^{[31-34]}$

The performance of corresponding photoanodes for water photoelectrolysis characterized under simulated AM $1.5 \mathrm{G}$ sunlight irradiation $\left(100 \mathrm{~mW} \mathrm{~cm} \mathrm{~cm}^{-2}\right)$ in $1 \mathrm{M} \mathrm{KOH}$ electrolyte is shown in Figure 2a. For the pristine $\alpha-\mathrm{Fe}_{2} \mathrm{O}_{3} \mathrm{NFs}$ photoanode under illumination, upon sweeping the potential from 0.6 to $1.7 \mathrm{~V}_{\mathrm{RHE}}$, a water oxidation onset potential of $0.6 \mathrm{~V}_{\mathrm{RHE}}$ is obtained and the photocurrent density is approximately $0.24 \mathrm{~mA} \mathrm{~cm}^{-2}$ at $1.23 \mathrm{~V}_{\mathrm{RHE}}$ and 0.58

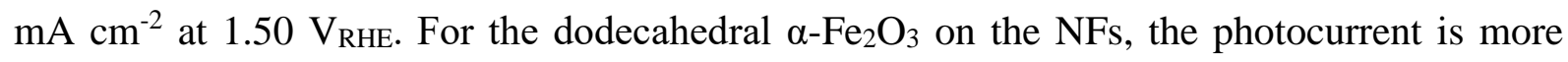
than doubled up to $0.57 \mathrm{~mA} \mathrm{~cm} \mathrm{~cm}^{-2}$ at $1.23 \mathrm{~V}_{\mathrm{RHE}}$. After $\mathrm{Sn}$ doping the onset potential slightly shifts to a more positive value, $0.73 \mathrm{~V}_{\mathrm{RHE}}$, while the photocurrent over the potential range from $0.8 \mathrm{~V}_{\mathrm{RHE}}$ to $1.7 \mathrm{~V}_{\mathrm{RHE}}$ is significantly increased to $2.4 \mathrm{~mA} \mathrm{~cm}{ }^{-2}$ and $3.5 \mathrm{~mA} \mathrm{~cm}^{-2}$ at 1.23 $\mathrm{V}_{\mathrm{RHE}}$ and 1.5 $\mathrm{V}_{\mathrm{RHE}}$, respectively. The calculated applied bias photon to current efficiency (ABPE) is determined to be $0.27 \%$ at $1.0 \mathrm{~V}_{\mathrm{RHE}}$ (Figure 2c). The superior performance obtained from the dodecahedral $\alpha-\mathrm{Fe}_{2} \mathrm{O}_{3}$ photoanode with $\{112\}$ facets on the NFs structure can be attributed to kinetic and light harvesting effects. Various polyhedron particle sizes and amounts were obtained by adjusting the immersion time, and the solar water splitting performance was examined (Figures $2 \mathbf{b}$ and S11). It can be seen that for the $\mathrm{Sn}$ doped $\alpha$ $\mathrm{Fe}_{2} \mathrm{O}_{3}$ polyhedron on the NFs for $48 \mathrm{~h}$, the photocurrent density is distinctly increased over the whole potential range, while for the shorter $(24 \mathrm{~h})$ or longer $(72 \mathrm{~h})$ growth times, the photoanodes exhibit a lower photoresponse but still show a higher value compared to the $\mathrm{Sn}$ 
doped $\mathrm{Fe}_{2} \mathrm{O}_{3} \mathrm{NFs}$ (Figures 2b). Especially, for the longer growth time of sample (72 h), even though it shows a much better light absorption (Figure S10), the lower photoresponse indicates a hampered water oxidation kinetics in compared to the optimum sample, most likely due to the aggregation of polyhedron particles that cover the whole NFs structure (Figure S4h).

For further enhancement in PEC performance, a FeOOH cocatalyst was decorated on the surface of the $\alpha-\mathrm{Fe}_{2} \mathrm{O}_{3}$ polyhedron. Figure 2a displays the PEC water splitting performance for a $\mathrm{FeOOH}$-decorated $\mathrm{Sn} / \alpha-\mathrm{Fe}_{2} \mathrm{O}_{3}$ polyhedron photoanode on NFs. Compared to the case of Sn doped $\alpha-\mathrm{Fe}_{2} \mathrm{O}_{3}$ polyhedron on NFs, the photocurrent density reaches up to $2.9 \mathrm{~mA} \mathrm{~cm}{ }^{-2}$ at $1.23 \mathrm{~V}_{\mathrm{RHE}}$, and a maximum photocurrent density of $4.5 \mathrm{~mA} \mathrm{~cm}{ }^{-2}$ at $1.5 \mathrm{~V}_{\mathrm{RHE}}$ is obtained with a cathodic shift of onset potential to $0.67 \mathrm{~V}_{\mathrm{RHE}}$. To the best of our knowledge, this is the highest value ever reported for polyhedron hematite photoanodes. Moreover, the photocurrent transient ratio values $\left(i_{\text {steady }} / i_{\text {initial }}\right)$ reach $0.65-0.80$ for the NFs or polyhedron hematite photoanodes, which even can be improved using Sn-doping or FeOOH decoration; here the $i_{\text {steady }} / i_{\text {initial }}$ values close to one are obtained (Figure 2d). Therefore, it can be deduced that the combination of polyhedron with $\{112\}$ facets anchored on the 1D flake structure and Sn doping are particularly effective in reducing/eliminating the decay of the photocurrent due to charge accumulation effects - i.e. charge transfer is strongly enhanced.

Figure 3a shows the results of incident photon-to-current conversion efficiencies (IPCEs) as a function of wavelength measured at $1.5 \mathrm{~V}_{\mathrm{RHE}}$ in $1 \mathrm{M} \mathrm{KOH}$. The IPCE values are in line with the measurements using AM 1.5G sun light irradiation (Figure 2a). The Sn doped $\alpha$ $\mathrm{Fe}_{2} \mathrm{O}_{3}$ polyhedron anchored on NFs photoanode with the decoration of FeOOH (Sn-D$\mathrm{NFs} / \mathrm{FeOOH}$ ) shows a drastic improvement for all photon wavelengths compared to the pristine hematite. More specifically, over the entire spectral range from $350 \mathrm{~nm}$ to $600 \mathrm{~nm}$ (Figure 3a), this photoanode shows the highest IPCE value, and a maximum IPCE value around $340 \mathrm{~nm}$ reaching 66\%. Moreover, in the range from 500 to $750 \mathrm{~nm}$ (inset of Figure 
3a), all the $\alpha-\mathrm{Fe}_{2} \mathrm{O}_{3}$ polyhedron on NFs, without and with doping or cocatalyst treatment, exhibit a higher IPCE than the pristine hematite NFs. This result indicates that the polyhedron exposed to $\{112\}$ facets on 1D structure is more efficient at long wavelength, consistent with the enhanced light absorption seen in UV-vis spectra (Figure 1j).

To further elucidate the correlation between the unique structure and the higher photoresponse, electrochemical impedance spectroscopy (EIS) measurements of corresponding photoanodes were carried out (Figure 3b). The semiconductor-electrolyte charge resistance $\left(\mathrm{R}_{\mathrm{ct}}\right)$ is a key parameter in characterizing the semiconductor-electrolyte charge-transfer process. In a Nyquist plot of the AC impedance data, the diameter of the semicircle reflects $\mathrm{R}_{\mathrm{ct}}$. In our case, $\mathrm{R}_{\mathrm{ct}}$ was calculated by fitting an equivalent circuit as shown in the inset of Figure S12 to the impedance data. In Figures $3 \mathbf{b}$ and $\mathbf{S 1 2}$, the $\mathrm{R}_{\mathrm{ct}}$ for the DNFs $(2735 \Omega)$ is obviously lower than that of the pristine NFs sample $(16037 \Omega)$. This may be attributed to the enhanced charge transfer provided by the D- $\{112\}$ planes. Further treatment with $\mathrm{Sn}$ doping and $\mathrm{FeOOH}$ cocatalyst, the $\mathrm{R}_{\mathrm{ct}}$ for the $\mathrm{Sn}-\mathrm{D}-\mathrm{NF} / \mathrm{FeOOH}(508 \Omega$ ) is clearly smaller than that of the D-NFs sample $(2735 \Omega)$. To further clarify the role on the enhanced charge electronic properties upon Sn doping and polyhedrons on 1D structure in $\mathrm{Fe}_{2} \mathrm{O}_{3}$, MottSchottky measurements were performed for the different samples (Figure S13). The obtained values for the Sn-D-NFs photoanodes without $\left(2.42 \times 10^{21} \mathrm{~cm}^{-3}\right)$ and with $\left(3.08 \times 10^{21} \mathrm{~cm}^{-3}\right)$ $\mathrm{FeOOH}$ decoration are twice around higher than that of the polyhedron on NFs $\left(4.47 \times 10^{20}\right.$ $\mathrm{cm}^{-3}$ ), in line with an increased carrier density created by Sn doping. In accord with above observations photoluminescence measurements showed the decay of photoluminescence intensity for the Sn-D-NFs sample to be slowed by Sn doping compared with that of the pristine $\alpha-\mathrm{Fe}_{2} \mathrm{O}_{3} \mathrm{NFs}$ (Figure S14), i.e. intrinsically a longer carrier life-time is provided.

Regarding the growth of high index plane polyhedron it should be noted that hematite single crystals during the growth processes usually expose low-index facets, such as $\{110\}$ and $\{012\} .{ }^{[35]}$ The high-index faceted nanocrystals are produced typically under specific 
energetic or seeding conditions. ${ }^{[36,37]}$ In this NF seed, a dodecahedral $\mathrm{Fe}_{3} \mathrm{O}_{4}$ crystal formed on the $\{110\}$ basal surfaces (Figure $\mathbf{S 4 i}$ ). In general, the facet growth rate is governed by the intrinsic surface energy. As a face-centered cubic (FCC) crystal, a general sequence of surface energies may hold, $\gamma\{111\}<\gamma\{100\}<\gamma\{110\}$ in a spinel oxide. ${ }^{[38]}$ The different terminated planes are composed of different $\mathrm{Fe}(\mathrm{III}) / \mathrm{Fe}(\mathrm{II})$ ratios. ${ }^{[39]}$ Therefore, the generating rate of $\mathrm{Fe}(\mathrm{II})$ reduced from $\mathrm{Fe}(\mathrm{III})$ likely affects the growth speed along different facets, which further determines the shapes of the polyhedrons. At a low concentration of $\left[\mathrm{Fe}^{3+}\right]=1 \mathrm{mM}$ and $2.5 \mathrm{mM}$, the irregular polyhedrons and many small particles are found (Figure S7), which indicates that there are two different shape determining routes in the process. Irregular polyhedrons as a result of Ostwald ripening, and the many small particles are generated due to irregular fast nucleation. Furthermore, in contrast to the $\mathrm{Fe}\left(\mathrm{NO}_{3}\right)_{3}$ solution, $\mathrm{FeCl}_{3}$ solutions do not lead to the formation of polyhedron particles but a uniform amorphous layer on the NFs (Figure S8). This can be attributed to $\mathrm{Cl}^{-}$that shows a strong coordination with $\mathrm{Fe}^{3+}$ and forms stable complexes, that reduce the nucleation probability of $\mathrm{Fe}_{3} \mathrm{O}_{4}$ crystals. ${ }^{[40]}$ A second key factor is the need of hematite NFs as a seeding layer that is essential to grow dodecahedrons that are crystallographically attached to the substrate.

These $\mathrm{Fe}_{3} \mathrm{O}_{4}$ dodecahedrons then can be transformed to $\mathrm{Fe}_{2} \mathrm{O}_{3}$ with $\{112\}$ facets during annealing in air. The hematite polyhedrons with $\{112\}$ facets represent a high surface energy state. ${ }^{[41]}$ The EIS and Mott-Schottky results (Figures 3b and S13) indicate that this faceting and the unique structure - polyhedron on 1D NFs - are a major factor in the improvement of PEC performance. The low charge resistance and high charge carrier density can be attributed to the $\{112\}$ facets which have a lower energy barriers for water oxidation, and due to active sites provided by low-coordinated atoms located on step edges. ${ }^{[42,43]}$ According to literature it is also remarkable that a hole hopping along the [112] direction crosses less $\mathrm{O}^{2-}$ ions than that along the other directions (e.g. [104]), and thus the hole can transfer to the surface at lower energy (faster) when more $\{112\}$ facets are exposed. ${ }^{[44,45]}$ 
In addition, the $1 \mathrm{D}$ support further improves the electron transfer from the polyhedrons to and across the back contact. The implementation of $\mathrm{Sn}$ doping and $\mathrm{FeOOH}$ decoration as a cocatalyst further increase the charge-transfer rate across the semiconductor-electrolyte interface, and facilitate the hole transfer at this interface. The photoluminescence decay spectra give additional support to the general finding that recombination of photogenerated carriers can be inhibited by Sn doping and is further reduced by the fast transfer at high-index faceted crystals. Above results thus demonstrate the advantage of high-index $\{112\}$ faceted nanocrystals grafted on a 1D structure as a photoelectrode and show that a suitable faceted polyhedron anchored on 1D structure leads to a remarkable improvement in PEC water oxidation.

\section{Conclusion}

In summary, we have demonstrated that the dodecahedral nanoparticles anchored on a one dimensional nanoflake structure represent a highly beneficial architecture for PEC water splitting. The photoanodes can be assembled by a sequence of simple thermal oxidation and precipitation methods. $\mathrm{Fe}_{2} \mathrm{O}_{3}$ nanoflakes act as seeds for the initiation of the growth of dodecahedral nanocrystals from an iron nitrate solution. These initial single crystals consist of $\mathrm{Fe}_{3} \mathrm{O}_{4}$ that then in a thermal step can be converted to hematite with high-index $\{112\}$ planes. The resulting single crystal (bi-crystal) hematite photoanode demonstrates a high efficiency for solar water splitting with an excellent photoresponse due to the direct grafting of the light harvesting and reactive sites to the transport geometry. We expect that the concept to graft functional single crystals with high-index crystal facets grafted on a 1D structure opens up new approaches for the assembly highly efficient PEC devices.

\section{Experimental Section}


For the preparation of dodecahedral $\alpha-\mathrm{Fe}_{2} \mathrm{O}_{3}$ anchored on $\mathrm{NFs}$.

Iron foils (Alfa Aesar, 99.99\%) were degreased by sonicating in acetone and ethanol for 10-20 minutes, followed by drying in a nitrogen stream. The samples then were thermally annealed in a furnace (Heraeus Furnace, ZEW 1451-4) in air at $400{ }^{\circ} \mathrm{C}$ for $2-3 \mathrm{~h}$ with a heating rate of $10{ }^{\circ} \mathrm{C} \mathrm{min}^{-1}$. For the dodecahedral $\mathrm{Fe}_{3} \mathrm{O}_{4}$ anchored on NFs (D-NFs-1), the $\alpha$ $\mathrm{Fe}_{2} \mathrm{O}_{3}$ NFs samples were immersed in a 1 5 mM Fe( $\left(\mathrm{NO}_{3}\right)_{3} \cdot 9 \mathrm{H}_{2} \mathrm{O}$ (Sigma-Aldrich, 98\%) aqueous solution for various times by a facile "top-down" method (The front sides of NFs were faced to the bottom), following by rinsing with distilled water and drying in a $\mathrm{N}_{2}$ stream. Then, the dodecahedral $\mathrm{Fe}_{3} \mathrm{O}_{4}$ anchored on NFs (D-NFs-1) were transformed to the dodecahedral $\alpha-\mathrm{Fe}_{2} \mathrm{O}_{3}$ on NFs (D-NFs) by an annealing treatment at $600{ }^{\circ} \mathrm{C}$ for several minutes. For the Sn doped dodecahedral $\alpha-\mathrm{Fe}_{2} \mathrm{O}_{3}$ on NFs (Sn-D-NFs), a $0.2 \mathrm{M} \mathrm{SnCl}_{4} \cdot 5 \mathrm{H}_{2} \mathrm{O}$ (Sigma-Aldrich, 99\%) ethanol solution was dropped on the dodecahedral $\mathrm{Fe}_{3} \mathrm{O}_{4}$ on NFs (DNFs-1). Then the samples were dried in a $\mathrm{N}_{2}$ stream. The samples were further annealed at $600{ }^{\circ} \mathrm{C}$ for several minutes. For the further decoration of $\mathrm{FeOOH}$ cocatalyst (Sn-DNFs/FeOOH), the samples (Sn-D-NFs) were immersed in a $5 \mathrm{mM} \mathrm{FeCl}_{3}$ (Sigma-Aldrich, $99 \%$ ) solution for $12 \mathrm{~h}$, following by rinsing with distilled water and drying in a $\mathrm{N}_{2}$ stream. For comparison, the $\alpha-\mathrm{Fe}_{2} \mathrm{O}_{3} \mathrm{NFs}$ samples were immersed in the $5 \mathrm{mM} \mathrm{FeCl}$ (Sigma-Aldrich, 99\%) aqueous solutions for various times. ${ }^{1}$ Meanwhile, the FTO substrates were treated in the $5 \mathrm{mM} \mathrm{Fe}\left(\mathrm{NO}_{3}\right)_{3}$ aqueous solutions at room temperature, following by rinsing with distilled water and drying in a $\mathrm{N}_{2}$ stream.

\section{Characterization.}

X-ray diffraction (X'pert Philips PRO with a Panalytical X'celerator detector, Germany) was carried out using graphite monochromized $\mathrm{Cu} \mathrm{K}_{\alpha}$ radiation (Wavelength $1.54056 \AA$ ). Chemical characterization was carried out by a X-ray photoelectron spectraoscopy (ESCALAB 250Xi, ThermoFisher Scientific). A field-emission scanning electrode microscope (Hitachi SU8020, Japan) was used for the morphological characterization of the 
electrodes. TEM analysis was performed on a TECNAI G ${ }^{2}$ TF20 microscope operated at 200 $\mathrm{kV}$. UV-vis diffuse reflectance spectra were taken on an UV-2550 (Shimadzu) spectrometer by using $\mathrm{BaSO}_{4}$ as the reference. The fluorescence decay times were measured using the Horiba Jobin Yvon Data Station HUB operating in time-correlated single photon counting mode (TCSPC) with the time resolution of 200 ps. Nano LED diode emitting pulse sat 454 $\mathrm{nm}$ with $1 \mathrm{MHz}$ repetition rate was used as an excitation source. Light-scattering Ludox solution was used to obtain the instrument response function (prompt). The time ranges are $0.055 \mathrm{~ns} /$ channel in 4096 effective channels.

\section{Photoelectrochemical performance.}

The photoelectrochemical experiments were carried out under simulated AM 1.5 (100 mW $\mathrm{cm}^{-2}$ ) illumination provided by a solar simulator (300 W Xe with optical filter, Solarlight; RT). The $1 \mathrm{M} \mathrm{KOH}$ aqueous solution was used as an electrolyte after saturation with $\mathrm{N}_{2}$ gas for 30 min. A three-electrode configuration was used in the measurement, with the $\alpha-\mathrm{Fe}_{2} \mathrm{O}_{3}$ electrode serving as the working electrode (photoanode), an $\mathrm{Ag} / \mathrm{AgCl}(3 \mathrm{M} \mathrm{KCl})$ as the reference electrode, and a platinum foil as the counter electrode. Photocurrent vs. voltage $(I-V)$ characteristics were recorded by scanning the potential from -0.4 to $0.7 \mathrm{~V}$ (vs. $\mathrm{Ag} / \mathrm{AgCl}$ (3 M $\mathrm{KCl})$ ) with a scan rate of $10 \mathrm{mV} \mathrm{s}^{-1}$ using a Jaissle IMP 88 PC potentiostat. The measured potentials vs. $\mathrm{Ag} / \mathrm{AgCl}(3 \mathrm{M} \mathrm{KCl})$ were converted to the reversible hydrogen electrode (RHE) scale using the relationship $\mathrm{E}_{\mathrm{RHE}}=\mathrm{E}_{\mathrm{Ag} / \mathrm{AgCl}}+0.059 \mathrm{pH}+\mathrm{E}_{0 \mathrm{Ag} / \mathrm{AgCl}}$, where $\mathrm{E}_{\mathrm{Ag} / \mathrm{AgCl}}$ is the experimentally measured potential and $\mathrm{E}_{0 \mathrm{Ag} / \mathrm{AgCl}}=0.209 \mathrm{~V}$ at $25^{\circ} \mathrm{C}$ for an $\mathrm{Ag} / \mathrm{AgCl}$ electrode in $3 \mathrm{M} \mathrm{KCl}$. The applied bias photon-to-current efficiency (ABPE) was caclulated by following equation:

$$
\operatorname{ABPE}(\%)=\frac{I\left(\mathrm{~mA} / \mathrm{cm}^{2}\right) \times\left(1.23-V_{\text {bias }}\right)(\mathrm{V})}{P_{\text {light }}\left(\mathrm{mW} / \mathrm{cm}^{2}\right)} \times 100
$$

where $I$ is the photocurrent density, $V_{\text {bias }}$ is the applied potential, $P_{\text {light }}$ is the incident illumination power density $\left(100 \mathrm{~mW} \mathrm{~cm}^{-2}\right)$. Photocurrent spectra were acquired at an applied 
potential of $1.5 \mathrm{~V}_{\mathrm{RHE}}$ in $1 \mathrm{M} \mathrm{KOH}$ recorded with $20 \mathrm{~nm}$ steps in the range of $300-750 \mathrm{~nm}$ using an Oriel $6365150 \mathrm{~W}$ Xe-lamp equipped with an Oriel Cornerstone 7400 1/8 m monochromator. IPCE was calculated as follow:

$$
\operatorname{IPCE}(\%)=\frac{1240 \times \mathrm{I}\left(\mathrm{mA} / \mathrm{cm}^{2}\right)}{P_{\text {light }}\left(\mathrm{mW} / \mathrm{cm}^{2}\right) \times \lambda(\mathrm{mm})} \times 100
$$

where $I$ is the measured photocurrent density at specific wavelength, $\lambda$ is the wavelength of incident light, and $P_{\text {light }}$ is the measured light power density at that wavelength. Electrochemical impedance spectroscopy (EIS) measurements were performed using a Chi760e electrochemical workstation (Huakeputian Technology Beijing). EIS measurements were performed by applying $1.23 \mathrm{~V}_{\mathrm{RHE}}$ at a frequency range of $10^{5} \mathrm{~Hz}$ to $0.01 \mathrm{~Hz}$ with an amplitude of $10 \mathrm{mV}$ under AM 1.5G $\left(100 \mathrm{~mW} \mathrm{~cm}^{-2}\right)$ illumination. The Mott-Schottky curves were obtained by using the Chi760e electrochemical workstation. Measurements were obtained in $1 \mathrm{M} \mathrm{KOH}$ under AM $1.5 \mathrm{G}$ illumination at a frequency of $1000 \mathrm{~Hz}$, amplitude +/$10 \mathrm{mV}$.

\section{Acknowledgements}

The authors would like to acknowledge the National Science Foundation of China (21622310, 21573264, 21633013), the ERC, the DFG, the Erlangen DFG cluster of excellence "Engineering of Advanced Materials", project EXC315, and the DFG funCOS for financial support. 


\section{References}

[1] T. Hisatomi, H. Dotan, M. Stefik, K. Sivula, A. Rothschild, M. Grätzel, N. Mathews, Adv. Mater. 2012, 24, 2699-2702.

[2] M. Liao, J. Feng, W. Luo, Z. Wang, J. Zhang, Z. Li, T. Yu, Z. Zou, Adv. Func. Mater. 2012, 22, 3066-3074.

[3] Y. Li, L. Zhang, A. Torres-Pardo, J. M. González-Calbet, Y. Ma, P. Oleynikov, O. Terasaki, S. Asahina, M. Shima, D. Cha, L. Zhao, K. Takanabe, J. Kubota, K. Domen, Nature Commun. 2013, 4, 2566.

[4] a) L. Wang, X. Zhou, N. T. Nguyen, I. Hwang, P. Schmuki, Adv. Mater. 2016, 28, 2432 -2438; b) J. Hou, Y. Wu, S. Cao, F. Liang, Z. Lin, Z. Gao, L. Sun, Adv. Energy Mater. 2017, DOI: 10.1002/aenm.201700171.

[5] a) T. W. Kim, K.-S. Choi, Science 2014, 343, 990-994; b) J. Su, L. Guo, N. Bao, C. A. Grimes, Nano Lett. 2011, 11, 1928-1933; c) Y. H. Ng, A. Iwase, A. Kudo, R. Amal, J. Phys. Chem. Lett. 2010, 1, 2607-2612.

[6] P. Dias, L. Andrade. A. Mendes, Nano Energy 2017, 38, 218-231.

[7] L. Wang, H. Hu, N. T. Nguyen, Y. Zhang, P. Schmuki, Y. P. Bi, Nano Energy 2017, $35,171-178$.

[8] a) C. Li, A. Li, Z. Luo, J. Zhang, X. Chang, Z. Huang, T. Wang, J. L. Gong, Angew. Chem. Int. Ed. 2017, 129, 4214-4219; b) Z. Luo, T. Wang, J. Zhang, C. Li, H. Li, J. L. Gong, Angew. Chem. Int. Ed. 2017, 56, 12878-12882.

[9] Gurudayal, R. A. John, P. P. Boix, C. Yi, C. Shi, M. C. Scott, S. A. Veldhuis, A. M. Minor, S. M. Zakeeruddin, L. H. Wong, M. Grätzel, N. Mathews, ChemSusChem 2017, 10, 2449-2456.

[10] J. S. Kang, Y. Noh, J. Kim, H. Choi, T. H. Jeon, D. Ahn, J.-Y. Kim, S.-H. Yu, H. Park, J.-H. Yum, W. Choi, D. C. Dunand, H. Choe, Y.-E. Sung, Angew. Chem. 2017, 129, 66836688. 
[11] B. Y. Geng, J. Z. Ma, J. H. You, Cryst. Growth Des. 2008, 8, 1443-1447.

[12] M. Lin, L. Tng, T. Lim, M. Choo, J. Zhang, H. R. Tan, S. Bai, J. Phys. Chem. C 2014, $118,10903-10910$.

[13] H. Song, X. Zhang, T. Chen, X. Jia, J. Mater. Sci.: Mater. Electron. 2014, 25, 55935600.

[14] W. Wu, R. Hao, F. Liu, X. Su, Y. Hou, J. Mater. Chem. A 2013, 1, 6888-6894.

[15] Z. Y. Zhou, N. Tian, J. T. Li, I. Broadwell, S. G. Sun, Chem. Soc. Rev. 2011, 40, 41674185.

[16] a) J. Ouyang, J. Pei, Q. Kuang, Z. Xie, L. Zheng, ACS Appl. Mater. Interfaces 2014, 6, 12505-12514; b) H. J. Song, X. H. Jia, X. Q. Zhang, J. Mater. Chem. 2012, 22, 22699-22705.

[17] S. Li, G. Qin, X. Meng, Y. Ren, L. Zuo, J. Mater. Sci. 2013, 48, 5744-5749.

[18] B. Lv, Z. Liu, H. Tian, Y. Xu, D. Wu, Y. Sun, Adv. Func. Mater. 2010, 20, 3987-3996.

[19] R. Xu, Y. Xu, Y. Huang, Y. Shi, B. Zhang, CrystEngComm. 2015, 17, 27-31.

[20] C. W. Wang, S. Yang, W. Q. Fang, P. Liu, H. Zhao, H. G. Yang, Nano Lett. 2016, 16, 427-433.

[21] S. Liu, L. Zheng, P. Yu, S. Han, X. Fang, Adv. Funct. Mater. 2016, 26, 3331-3339.

[22] a) S. Kement, F. Riboni, S. Pausova, L Wang, L. Y. Wang, H. Han, Z. Hubicka, J. Krysa, P. Schmuki, R. Zboril, Chem. Soc. Rev. 2017, 46, 3716-3769; b) P. Roy, S. Berger, P. Schmuki, Angew. Chem. Int. Ed. 2011, 50, 2904-2939.

[23] I. Chamritski, G. Burns, J. Phys. Chem. B 2005, 109, 4965-4968.

[24] J.-F. Lu, C.-J. Tsai, Nanoscale Res. Lett. 2014, 9, 230.

[25] Y. Xiong, Y. Xia, Adv. Mater. 2007, 19, 3385-3391.

[26] Y. P. Bi, H. Hu, S. Ouyang, Z. Jiao, G. Lu, J. H. Ye, J. Mater. Chem. 2012, 22, 1484714850.

[27] H. Cao, X. Qian, C. Wang, X. Ma, J. Yin, Z. Zhu, J. Am. Chem. Soc. 2005, 127, 16024 $-16025$. 
[28] L. Wang, N. T. Nguyen, Y. Zhang, Y. P. Bi, P. Schmuki, ChemSusChem 2017, 10, $2720-2727$.

[29] J. Wang, W. B. White, J. H. Adair, J. Am. Ceram. Soc. 2005, 88, 3449-3454.

[30] D. A. Wheeler, G. Wang, Y. Ling, Y. Li, J. Z. Zhang, Energy Environ. Sci. 2012, 5, $6682-6702$.

[31] R. M. Cornell, U. Schwertmann, The Iron Oxides: Structure, Properties, Reactions, Occurrences and Uses, Wiley-VCH Verlag, Weinhein, 2003.

[32] J. Y. T. Chan, S. Y. Ang, E. Y. Ye, M. Sullivan, J. Zhang, M. Lin, Phys. Chem. Chem. Phys. 2015, 17, 25333-25341.

[33] L. Chen, X. Yang, J. Chen, J. Liu, H. Wu, H. Zhan, C. Liang, M. Wu, Inorg. Chem. 2010, 49, 8411-8420.

[34] Y. Yang, H. Ma, J. Zhuang, X. Wang, Inorg. Chem. 2011, 50, 10143-10151.

[35] a) J. Chen, L. Wu, W. Li, X. Gou, Adv. Mater. 2005, 17, 582-586; b) C.-J. Jia, L.-D.

Sun, Z.-G. Yan, L.-P. You, F. Luo, X.-D. Han, Y.-C. Pang, Z. Zhang, C.-H. Yan, Angew. Chem. 2005, 117, 4402-4407.

[36] a) D. Wang, H. Chou, C. Cheng, Y. Wu. C. Tsai, H. Lin, Y. Wang, B. Hwang, C. Chen, Nano Energy 2015, 11, 631-639; b) N. Zhang, L. Bu, S. Guo, J. Guo, X. Huang, Nano Lett. 2016, 16, 5037-5043; c) Z. Wang, G. Zou, W. Wang, Z. Tang, Y. Bi, X. Wang, J. Power Source 2017, 343, 94-102.

[37] C.-H. Kuo, Y.-C. Yang, S. Gwo, M. H. Huang, J. Am. Chem. Soc. 2011, 133, 10521057.

[38] C. -H. Ho, C.-P. Tsai, C.-C. Chung, C.-T. Tsai, F.-R. Chen, H.-J. Lin, C.-H. Lai, Chem. Mater. 2011, 23, 1753-1760.

[39] C. Cheng, Phy. Rev. B 2005, 24, 720-725.

[40] L. Chen, Q. Zhou, Q. Xiong, W. Li, J. Liu, X. Yang, Adv. Mater. Sci. Eng. 2015, DOI: $10.1155 / 2015 / 763124$ 
[41] U. Aschauer, F. Jones, W. Richmond, P. Bowen, A. L. Rohl, G. M. Parkinson, H.

Hofman, J. Cryst. Growth 2008, 310, 688-698.

[42] J. Y. Li, S. L. Xiong, J. Pan, Y. T. Qian, J. Phys. Chem. C 2010, 114, 9645-9650.

[43] a) Z. Liu, B. Lv, Y. Xu, D. Wu, J. Mater. Chem. A 2013, 1, 3040-3046; b) Z. Liu, B.

Lv, D. Wu, Y. Sun, Y. Xu, Eur. J. Inorg. Chem. 2012, 4076-4081.

[44] X. J. Zhang, A. X. Gu, G. F. Wang, B. Fang, Q. Y. Yan, J. X. Zhu, T. Sun, J. Ma, H. H. Hng, CrystEngComm. 2011, 13, 188-192.

[45] J. Zheng, W. Zhou, Y. Ma, W. Cao, C. Wang, L. Guo, Chem. Commun. 2015, 51, 12863-12866. 
(a) $\mathrm{Fe}_{2} \mathrm{O}_{3} \mathrm{NFs}$

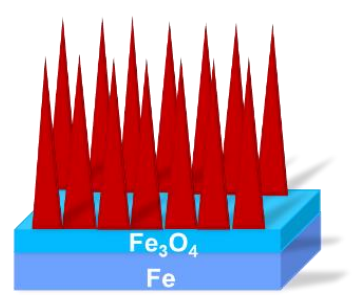

(b) $\mathrm{Fe}_{3} \mathrm{O}_{4}$ particles on NFs

Nucleation

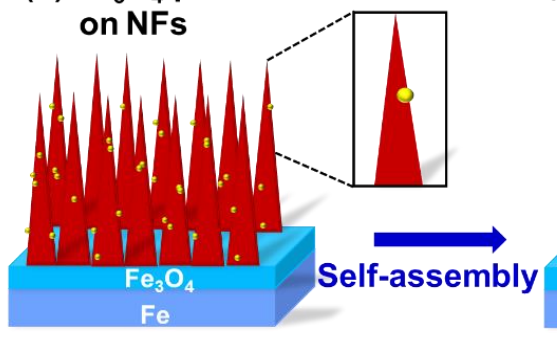

(e) $\mathrm{Fe}_{2} \mathrm{O}_{3}$ polyhedron on NFs
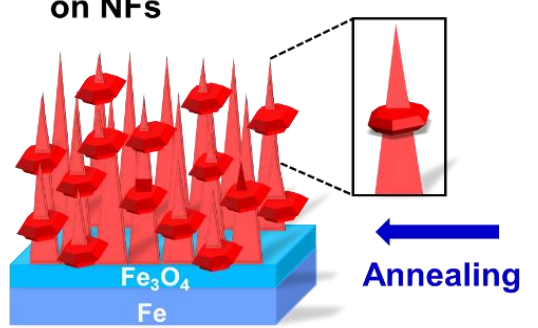

(c) $\mathrm{Fe}_{3} \mathrm{O}_{4}$ polyhedron on NFs

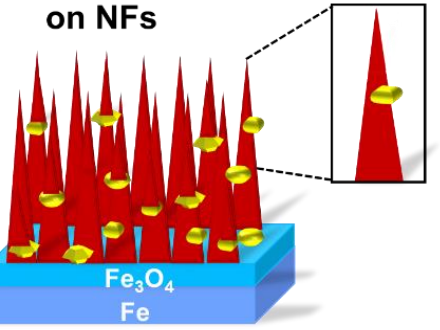

Oriented attachment

(d) $\mathrm{Fe}_{3} \mathrm{O}_{4}$ polyhedron on NFs

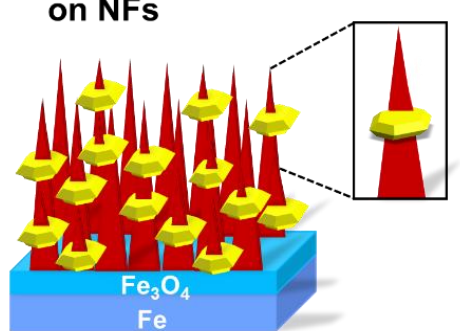

Scheme 1 Schematic illustration of synthesis process of dodecahedron $\mathrm{Fe}_{2} \mathrm{O}_{3}$ on NFs. (a) $\mathrm{Fe}_{2} \mathrm{O}_{3}$ NFs formed on iron foil by thermal oxidation method $\left(400{ }^{\circ} \mathrm{C}\right)$; (b) step 1: $\mathrm{Fe}_{3} \mathrm{O}_{4}$ nanoparticles grown on $\mathrm{Fe}_{2} \mathrm{O}_{3} \mathrm{NF}$ by immersion synthesis; (c) step 2: $\mathrm{Fe}_{3} \mathrm{O}_{4}$ nanopolyhedrons grown on $\mathrm{Fe}_{2} \mathrm{O}_{3} \mathrm{NFs}$; (d) step 3: $\mathrm{Fe}_{3} \mathrm{O}_{4}$ dodecahedrons grown on $\mathrm{Fe}_{2} \mathrm{O}_{3} \mathrm{NFs}$; (e) step 4: $\mathrm{Fe}_{2} \mathrm{O}_{3}$ dodecahedrons grown on $\mathrm{Fe}_{2} \mathrm{O}_{3} \mathrm{NFs}$ after thermal treatment $\left(600{ }^{\circ} \mathrm{C}\right)$. 

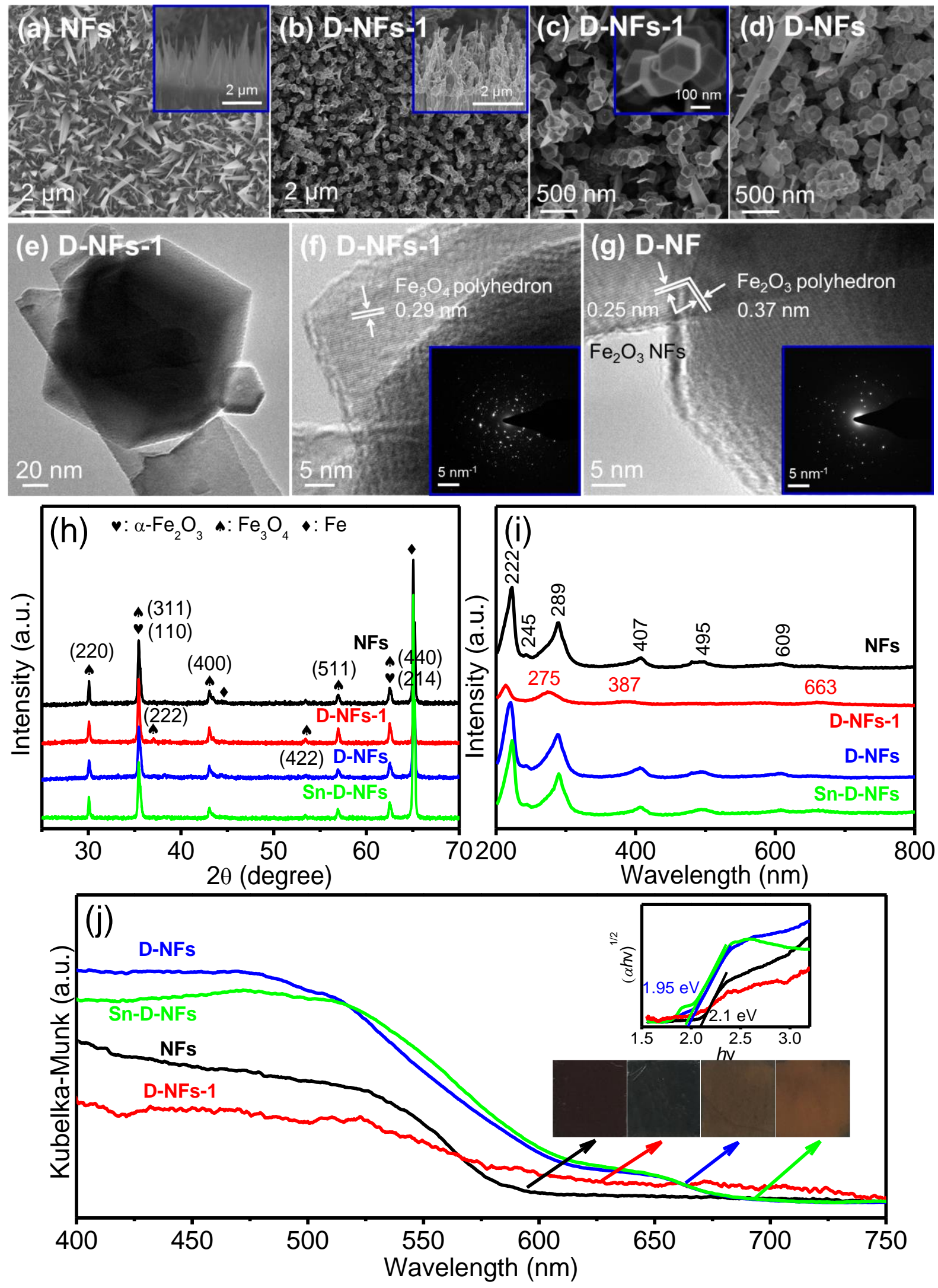
Figure 1 (a-d) SEM top and cross-sectional images of (a) $\mathrm{Fe}_{2} \mathrm{O}_{3} \mathrm{NFs}$, (b,c) dodecahedron $\mathrm{Fe}_{3} \mathrm{O}_{4}$ on NFs; (d) dodecahedron $\mathrm{Fe}_{2} \mathrm{O}_{3}$ on NFs; (e-g) TEM images of (e,f) dodecahedron $\mathrm{Fe}_{3} \mathrm{O}_{4}$ on NFs and (g) dodecahedron $\mathrm{Fe}_{2} \mathrm{O}_{3}$ on NFs. Insets of (f) and (g) show SAD patterns of corresponding samples; (h) XRD patterns, (i) Raman spectra, and (j) UV-Vis absorption spectra of corresponding samples. Inset of (j) shows band gaps of samples from reflectance data, and optical images of samples. $\mathrm{Fe}_{2} \mathrm{O}_{3}$ NFs: NFs; D-NFs-1: dodecahedron $\mathrm{Fe}_{3} \mathrm{O}_{4}$ on NFs; D-NF: dodecahedron $\mathrm{Fe}_{2} \mathrm{O}_{3}$ on NFs (dodecahedron $\mathrm{Fe}_{3} \mathrm{O}_{4}$ on $\mathrm{NFs}$ was annealed at $600{ }^{\circ} \mathrm{C}$ ); Sn-D-NFs: $\mathrm{Sn}$ treated dodecahedron $\mathrm{Fe}_{2} \mathrm{O}_{3}$ on NFs ( $\mathrm{Sn}$ treated dodecahedron $\mathrm{Fe}_{3} \mathrm{O}_{4}$ on $\mathrm{NFs}$ was annealed at $600{ }^{\circ} \mathrm{C}$ ). 
(a)
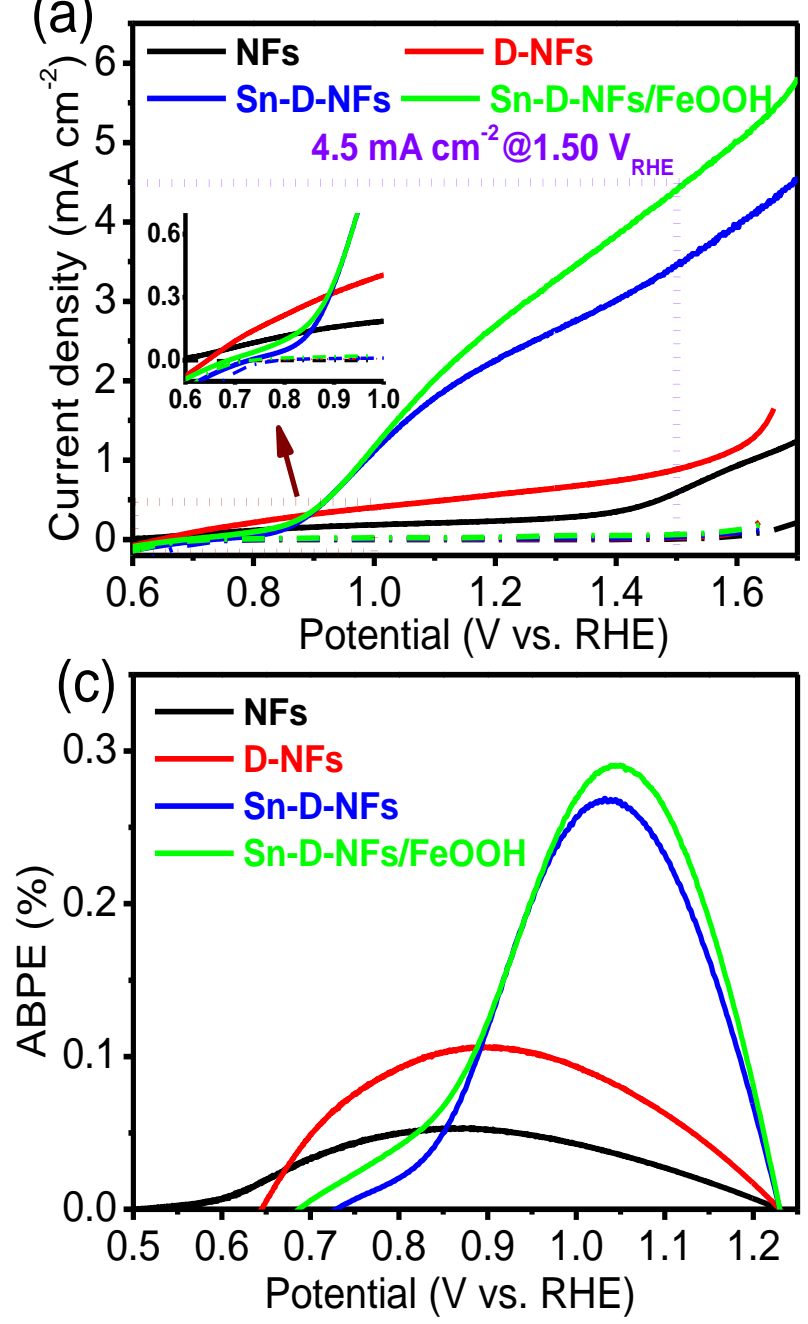
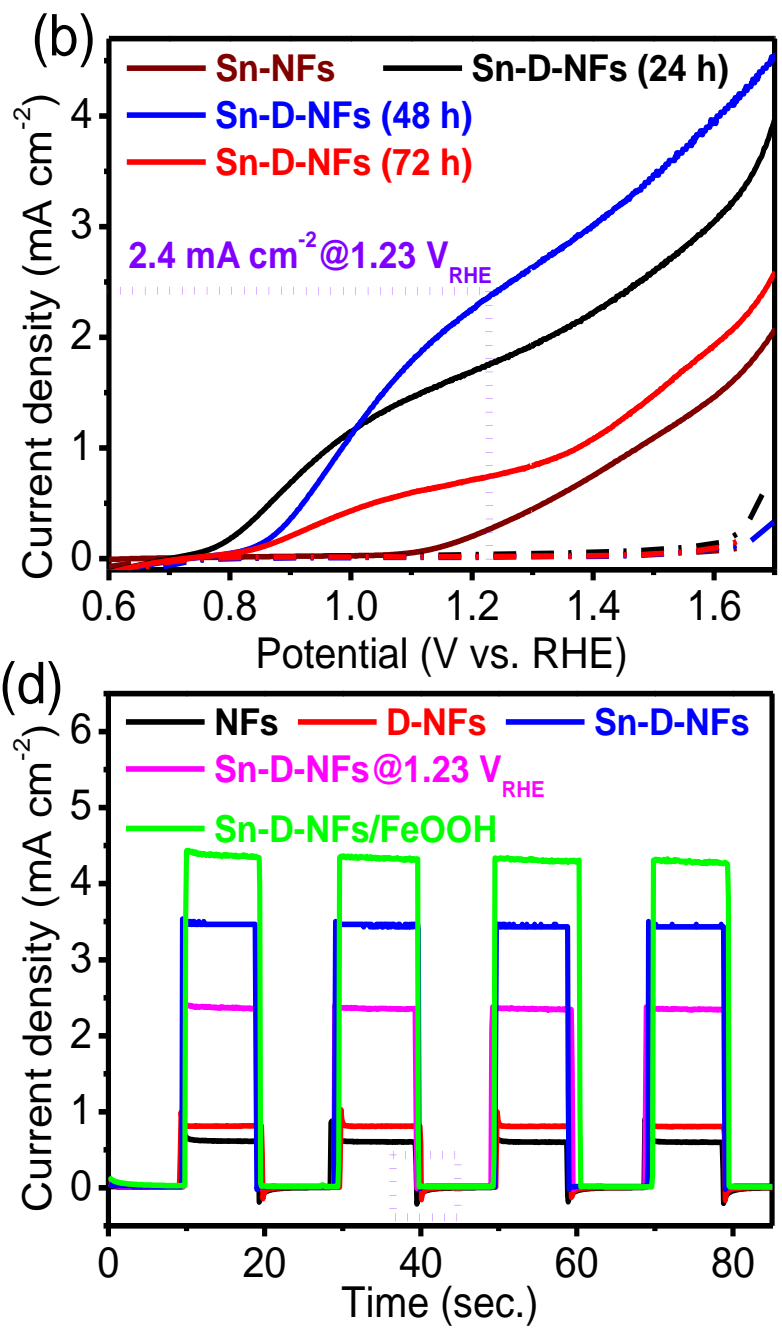

Figure 2 (a) Linear-sweep voltammogram (LSV) curves of NFs, D-NFs, Sn-D-NFs, and SnD-NFs/FeOOH; (b) LSV curves of Sn-D-NFs for various immersion times in $\mathrm{Fe}\left(\mathrm{NO}_{3}\right)_{3}$ solutions. The Sn doped NFs (Sn-NFs) was examined for comparison. Line-in light; Dash dot-in dark; (c) applied bias photon-to-current efficiencies (ABPEs), (d) $i$ - $t$ curves at $1.5 \mathrm{~V}_{\mathrm{RHE}}$ of NFs, D-NFs, Sn-D-NFs, and Sn-D-NFs/FeOOH. The solar water splitting experiments were carried out in $1 \mathrm{M} \mathrm{KOH}$ electrolyte under AM $1.5 \mathrm{G}\left(100 \mathrm{~mW} \mathrm{~cm}^{-2}\right)$ illumination. 


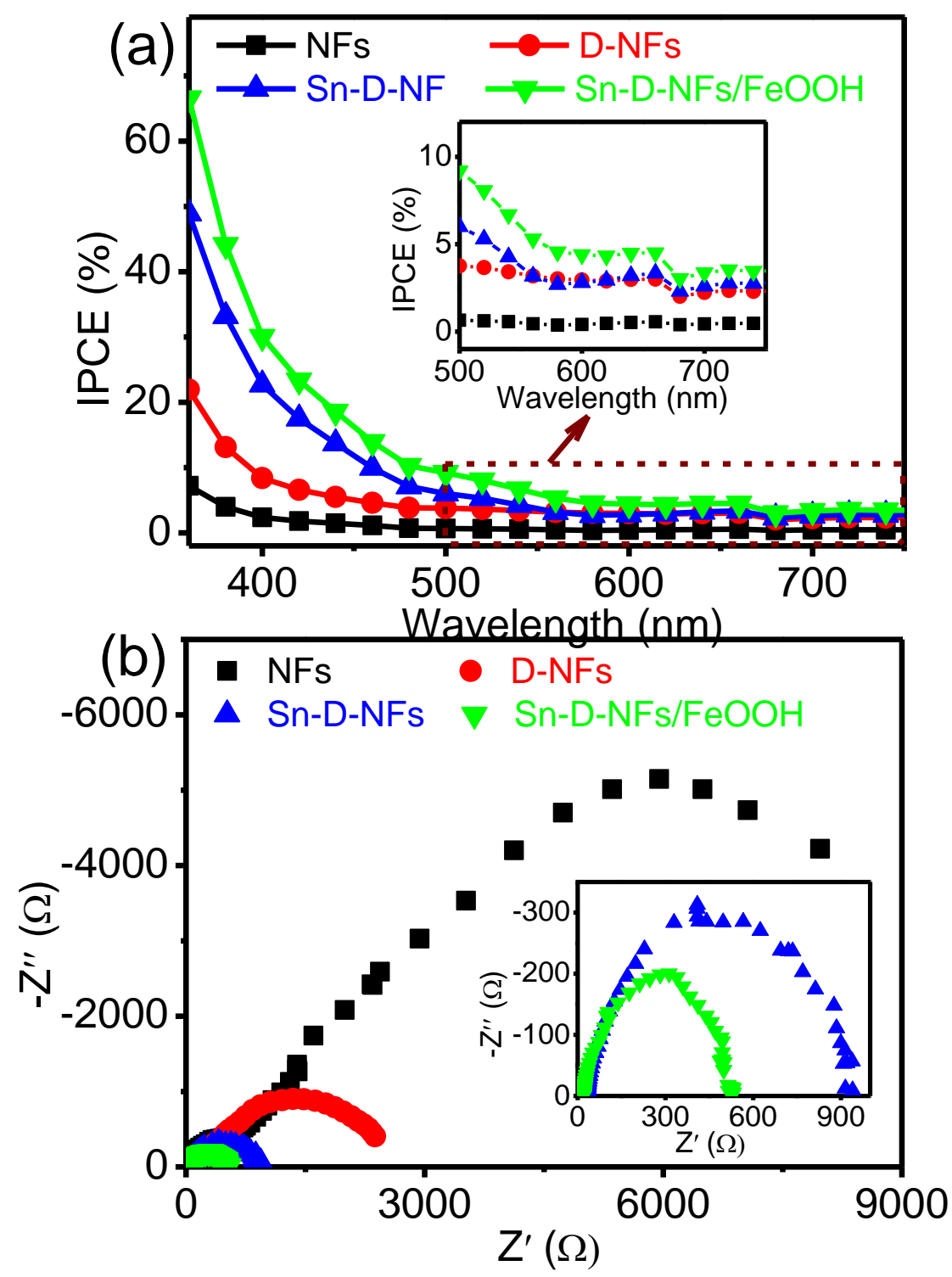

Figure 3 (a) Incident photon-to-current conversion efficiencies (IPCEs), (b) electrochemical impedance spectroscopy (EIS) of NFs, D-NFs, Sn-D-NFs, and Sn-D-NFs/FeOOH. The EIS measurements were carried out in $1 \mathrm{M} \mathrm{KOH}$ at $1.23 \mathrm{~V}_{\mathrm{RHE}}$ under $\mathrm{AM} 1.5 \mathrm{G}$ illumination. 